\title{
The Impact of Educational Status on 10-Year (2004-2014) Cardiovascular Disease Prognosis and All-cause Mortality Among Acute Coronary Syndrome Patients in the Greek Acute Coronary Syndrome (GREECS) Longitudinal Study
}

\author{
Venetia Notara', Demosthenes B. Panagiotakos' ${ }^{1}$, Yannis Kogias ${ }^{2}$, Petros Stravopodis ${ }^{3}$, Antonis Antonoulas ${ }^{4}$, \\ Spyros Zombolos ${ }^{5}$, Yannis Mantas ${ }^{6}$, Christos Pitsavos ${ }^{7}$; GREECS Study Investigators \\ ${ }^{1}$ Department of Nutrition and Dietetics, School of Health Science and Education, Harokopio University, Athens; ${ }^{2}$ Cardiology Clinic, \\ General Hospital of Karditsa, Karditsa; ${ }^{3}$ Cardiology Clinic, General Hospital of Zakynthos Island, Zakynthos; ${ }^{4}$ Cardiology Clinic, General \\ Hospital of Lamia, Lamia; ${ }^{5}$ Cardiology Clinic, General Hospital of Kalamata, Kalamata; ${ }^{6}$ Cardiology Clinic, General Hospital of Chalkida, \\ Chalkida; ${ }^{7}$ First Cardiology Clinic, School of Medicine, University of Athens, Athens, Greece
}

Objectives: The association between educational status and 10-year risk for acute coronary syndrome (ACS) and all-cause mortality was evaluated.

Methods: From October 2003 to September 2004, 2172 consecutive ACS patients from six Greek hospitals were enrolled. In 2013 to 2014, a 10-year follow-up (2004-2014) assessment was performed for 1918 participants (participation rate, 88\%). Each patient's educational status was classified as low ( $<9$ years of school), intermediate (9 to 14 years), or high ( $>14$ years).

Results: Overall all-cause mortality was almost twofold higher in the low-education group than in the intermediate-education and high-education groups ( $40 \%$ vs. $22 \%$ and $19 \%$, respectively, $p<0.001$ ). Additionally, 10 -year recurrent ACS events (fatal and non-fatal) were more common in the low-education group than in the intermediate-education and high-education groups ( $42 \%$ vs. $30 \%$ and $35 \%, p<0.001$ ), and no interactions between sex and education on the investigated outcomes were observed. Moreover, patients in the high-education group were more physically active, had a better financial status, and were less likely to have hypertension, diabetes, or ACS than the participants with the least education $(p<0.001)$; however, when those characteristics and lifestyle habits were accounted for, no moderating effects regarding the relationship of educational status with all-cause mortality and ACS events were observed.

Conclusions: A U-shaped association may be proposed for the relationship between ACS prognosis and educational status, with participants in the low-education and high-education groups being negatively affected by other factors (e.g., job stress, depression, or loneliness). Public health policies should be aimed at specific social groups to reduce the overall burden of cardiovascular disease morbidity.

Key words: Cardiovascular disease, Acute coronary syndrome, Educational staus, Social class, Risk factors, Unhealthy behaviors

Received: January 14, 2016 Accepted: June 24, 2016

Corresponding author: Demosthenes B. Panagiotakos, PhD 46 Paleon Polemiston St., Glyfada 166 74, Greece

Tel: +30-210-9603116, Fax: +30-210-9600719

E-mail: d.b.panagiotakos@usa.net

This is an Open Access article distributed under the terms of the Creative Commons Attribution Non-Commercial License (http://creativecommons.org/licenses/bync/4.0/) which permits unrestricted non-commercial use, distribution, and reproduction in any medium, provided the original work is properly cited.

\section{INTRODUCTION}

Associations between educational status and the development of chronic diseases have been examined in several studies published over the last decades [1,2]. Recently, the US National Bureau of Economic Research [3] stated that each additional four years of education lowered all-cause mortality by 
almost $1.8 \%$ and reduced the risk of heart disease by $2.2 \%$. Socioeconomic factors also seem to be implicated in the relationship between education and cardiac health $[4,5]$. The CARDIO2000 case-control study was one of the first to report an increased incidence of acute coronary syndrome (ACS) among participants with low levels of education [6]. A recent World Health Organization (WHO) report indicated that deaths due to cardiovascular disease (CVD) are especially prevalent in lowincome and middle-income countries due to unequal living conditions, the mal-distribution of health care, and poor social policies [7]. In contrast, strong evidence indicates that higher educational levels are associated with lower CVD risk and better health status in general $[1,2]$.

However, the effect of educational attainment on the prevention of secondary ACS has not been thoroughly examined. Disease management, including better control of lifestyle risk factors and adherence to drug treatment, has been related to socioeconomic status, and in particular education levels. Moreover, it has been reported that patients with less formal education may be less likely to be properly diagnosed, and consequently less likely to receive adequate treatment, due to difficulties in communication between doctors and patients $[8,9]$. Social gradients in health and disease deserve further attention at the present moment given the global financial crisis that affects numerous people as well as the healthcare system as a whole. In light of the above considerations, and within the context of the Greek acute coronary syndrome (GREECS) study, which is a prospective cohort of 2172 ACS patients from Greece [10], the aim of this study was to evaluate associations between cardiac patients' educational status and 10-year recurrent ACS events (2004-2014), as well as all-cause mortality, taking into consideration various sociodemographic, lifestyle/ behavioral, and clinical factors that may elucidate the relationship in question. The strengths of the present study include the high participation rate (88\%) over the entire 10 years of follow-up and the inclusion of ACS patients from different regions (urban and rural) to increase the generalizability of the results.

\section{METHODS}

\section{Sampling Procedure and 10-Year Follow-up}

From October 2003 to September 2004, almost all consecutive patients $(n=2172)$ with a discharge diagnosis of ACS (i.e., acute myocardial infarction [AMI] or unstable angina) who had been hospitalized in the cardiology clinics or the emergency units of six major general hospitals in Greece (Hippokration Hospital in Athens and the general prefectural hospitals in Lamia, Karditsa, Halkida, Kalamata, and the island of Zakynthos) were enrolled in the study, with participation rates ranging from $80 \%$ to $95 \%$. Of the enrolled patients, 1649 (76\%) were males (mean age, $65 \pm 13$ years) and 523 (24\%) were females (mean age, $62 \pm 11$ years). With the exception of Athens, where there are several other hospitals, all the other hospitals cover the entire populations of the relevant regions, including urban and rural areas. The hospitals were selected in order to represent populations with diverse socioeconomic, cultural and regional characteristics. In 2014, a 10-year follow-up (2004 -2014) of the patients was performed through face-to-face interviews by the investigators. Of the initially enrolled participants, 1918 participated in the follow-up (participation rate, $88 \%)$. The remaining 254 patients (11.7\%) who were lost to the 10-year follow-up were considered to be censored.

\section{Baseline Diagnosis of Acute Coronary Syndrome and Measurements}

At the time of admission, as well as during the course of hospitalization (at 6 to 9 hours, and again at 12 to 24 hours if earlier samples were negative but the clinical index of suspicion was high) biomarkers suggesting cardiac injury and AMI were measured in each patient, including troponin I, creatine phosphokinase (CK), and the MB fraction of total CK (CK-MB). Moreover, a 12-lead electrocardiogram (ECG) was performed and clinical symptoms were evaluated in all patients by a cardiologist involved in the study. AMI was defined by the typical rise and gradual fall (troponin) or more rapid rise and fall (CK$\mathrm{MB}$ ) of biochemical markers of myocardial necrosis accompanied by at least one of the following: (1) ischemic symptoms, (2) development of pathologic S-T segment elevations on the ECG, (3) ECG changes indicative of ischemia (S-T segment elevation or depression) or (4) a coronary artery intervention (e.g. coronary angioplasty) [11]. Unstable angina was defined as the occurrence of one or more episodes of angina at rest within the preceding 48 hours, corresponding to class III of the Braunwald classification [12].

We evaluated the following sociodemographic and lifestyle characteristics: age, sex, physical activity, dietary and smoking habits, years of education, and financial status. In particular, educational status, which was the main exposure factor analyzed in the present work, was classified as low ( $<9$ years of 
school), intermediate (9 to 14 years or technical/vocational school) and high (>14 years). These cut-off values were used because a cut-off of 9 years corresponds to the obligatory level of education, a cut-off of 14 years represents subjects who completed technical/vocational education, and subjects who completed $>14$ years entered college. Patients' self-reported mean household annual income over the last three years was recorded. Their usual dietary intake over the year preceding enrollment was assessed by a semi-quantitative food frequency questionnaire, and level of adherence to the Mediterranean dietary pattern was calculated using the MedDietScore (range, 0 to 55) [13]. A modified version of the self-reported questionnaire provided by the American College of Sports Medicine was used to evaluate patients' physical activity during the previous year [14]. Current smokers were defined as those who smoked at least one cigarette per day at the time of enrollment or had stopped smoking cigarettes during the previous 12 months. The medical history assessment included each patients' history of hypertension, hypercholesterolemia, diabetes mellitus, and CVD, as well as the techniques used to manage these conditions. All patients were also asked about adherence to medication prescribed for hypertension, diabetes, dyslipidemia, nephropathy, and pre-existing CVD. Body mass index (BMI) was calculated as weight $(\mathrm{kg})$ divided by height squared $\left(m^{2}\right)$.

Further details about the procedures and measurements of the GREECS study may be found elsewhere [10].

\section{Endpoints at 10-Year Follow-up}

The endpoints studied in the 10-year follow-up of the study were: (1) all-cause mortality and (2) recurrent fatal or non-fatal ACS events. In particular, we recorded the occurrence of new AMls, angina pectoris, other forms of ischemia (International Classification of Diseases, 9th edition [ICD-9] codes 410.0$414.9,427.2$, and 427.6), heart failure of different types, and chronic arrhythmias (ICD-9 codes 400.0-404.9, 427.0-427.5, and 427.9). Information regarding each patient's baseline medical history and 10-year endpoints was retrieved through their medical records or hospital registries.

\section{Statistical Analysis}

Continuous variables are presented as mean values \pm standard deviation, while categorical variables are presented as absolute ( $\mathrm{n}$ ) and relative (\%) frequencies. Associations between normally distributed continuous variables and educa- tion status were evaluated through analysis of variance, after controlling for equality of variances (homoscedasticity). Due to multiple comparisons, the Bonferroni rule was applied to correct for the inflation of type I errors. Associations between categorical variables were tested by the use of the chi-square test. Correlations between continuous variables were evaluated by the use of Pearson's correlation coefficient for normally distributed variables and by the use of Spearman's rho coefficient for ordinal or skewed variables. Associations between patients' education status and 10-year outcomes were evaluated by the use of nested Cox proportional hazard models; the nested models were used to evaluate the potential moderating or mediating effects of various patient characteristics on the research hypothesis. The proportionality of the hazards was graphically tested by plotting the logarithm [-log(survival)] vs. the logarithm of elapsed time. Appropriate tests for goodness-of-fit (i.e., deviance and Pearson's residuals) were applied. For the 254 censored cases, information was taken from their 1-year follow-ups. The results are presented as hazard ratios (HRs) and their corresponding 95\% confidence intervals (Cls). The $p$-values $<0.05$ were considered to indicate statistical significance. All statistical calculations were performed using SPSS version 21.0 (IBM SPSS Inc., Athens, Greece).

\section{Bioethics}

The study was approved by the medical research ethics committee of the participating institutions and was carried out in accordance with the Declaration of Helsinki (1989) of the World Medical Association. Participants were informed about the aims and procedures of the study and provided written informed consent.

\section{RESULTS}

\section{All-cause Mortality and 10-Year Acute Coronary Syndrome Events}

The crude overall all-cause mortality was 32.4 per 100 population $(\mathrm{n}=703)(31.6 \%$ in males, $34.8 \%$ in females, $p=0.17)$; $52.8 \%$ of deaths were due to $\mathrm{AMI}, 8.3 \%$ were due to stroke, $8.3 \%$ were due to other CVD events, $8.7 \%$ were due to cancer, and the remaining $21.9 \%$ were due to other causes. The incidence of fatal or non-fatal 10-year recurrent ACS events were 37.3 per 100 population $(n=811)(38.8 \%$ in males and $32.9 \%$ in females, $p=0.02$ ). Moreover, the median survival time was 8.08 years for males and 7.78 years for females $(p=0.07)$; thus, 
the all-cause mortality rate was 404 deaths per 10000 population and the recurrent ACS events rate (fatal or non-fatal) was 466 per 10000 population.

\section{Distribution of Baseline Demographic, Lifestyle,} and Clinical Characteristics By Educational Status

Patients in the low-education group were older than those in the intermediate-education and high-education groups, reported more years of active smoking, and were less likely to follow a healthy diet or to have a comfortable financial status ( $p<0.001$ for all variables). In contrast, patients with higher educational levels were more likely to be physically active, had diets that were more similar to the traditional Mediterranean diet, and were less likely to have a history of hypertension or diabetes or a family history of CVD in comparison to patients with lower educational levels $(p<0.001)$; however, they were more likely to be obese $(p=0.05)$. Patients from the low-education group were less likely to have a history of hypercholesterolemia than patients from the high-education group $(p<0.001)$. Furthermore, it was observed that patients in the low-education and intermediate-education groups were less likely to comply with their prescribed medication for various comorbidities in comparison with the high-education group $(p<0.001)$ (Table 1).

\section{All-cause Mortality By Education Level During the 10-Year (2004-2014) Follow-up of Acute Coronary Syndrome Patients}

Univariate analysis showed that overall all-cause mortality was almost twofold higher in the low-education group than in the intermediate-education and high-education groups ( $p<$ 0.001 ). This difference was lower among females than among males $(p<0.001)$ (Table 2).

Moreover, the median follow-up time for the low-education group was much lower than for the intermediate-education and high-education groups (7.4 vs. 8.8 and 8.9 years, respectively (data not presented in Table 2).

In order to account for the potential confounding of patient characteristics on associations between education status and all-cause mortality, multivariate analysis was applied. Intermediate and low education levels were positively associated with all-cause mortality after adjusting for various potential confounders (Table 3). In particular, ACS patients with a low level of education had a $53 \%$ higher risk for all-cause mortality dur-

Table 1. Baseline demographic, lifestyle, and clinical characteristics of participants in the GREECS study by education status $(n=2172)$

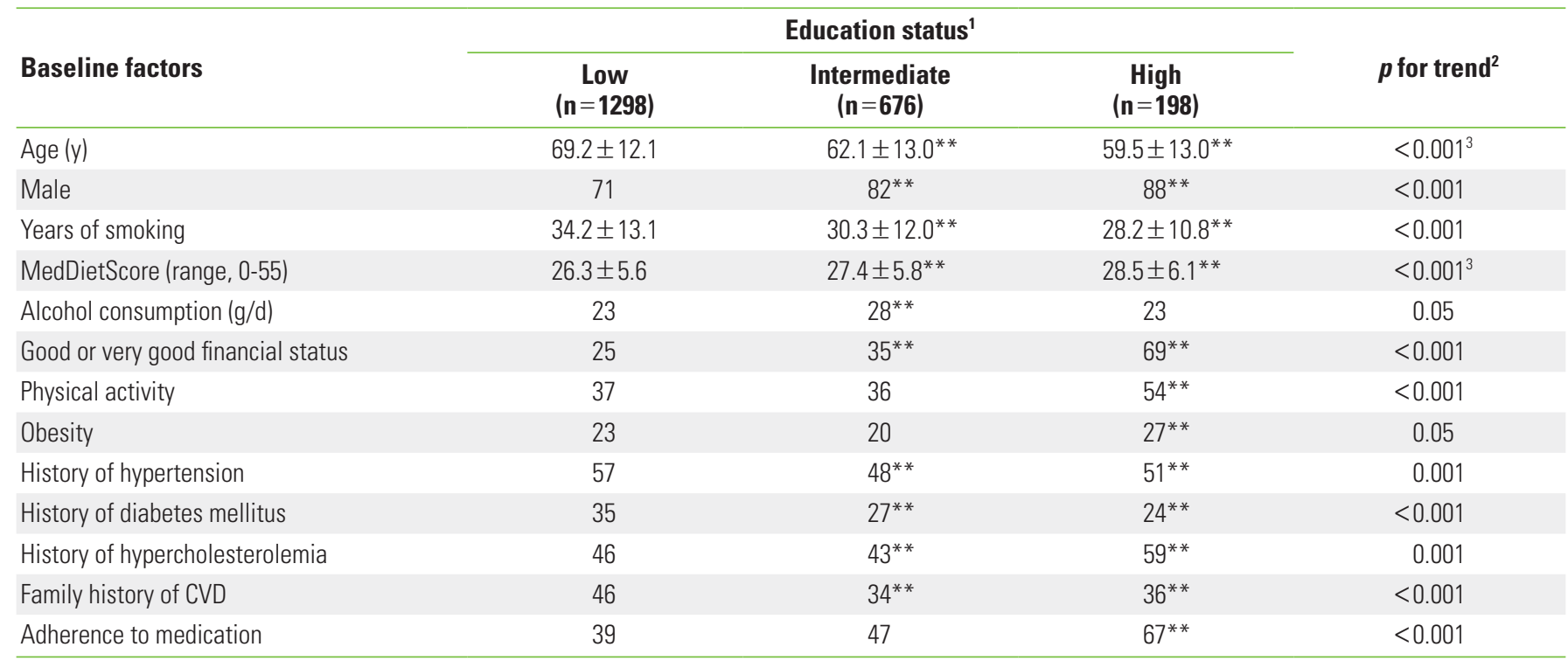

Values are presented as mean \pm standard deviation or \% frequency.

GREECS, Greek acute coronary syndrome; CVD, cardiovascular disease.

${ }^{1}$ Low education was defined as $<9$ years of school, intermediate education as 9-14 years of school, and high education as $>14$ years of school.

${ }^{2}$ Chi-square test was used to compare baseline factors between groups.

${ }^{3}$ Analysis of variance was used to compare baseline factors between groups.

${ }^{* *} p<0.01$ for comparisons between the high- and intermediate-education group versus the low-education group, after using the Bonferroni rule to correcting for the probability of the inflation of type I errors due to multiple comparisons. 
Table 2. Results of the unadjusted analysis of10-year recurrent ACS events (fatal or non-fatal) according to the education status of the GREECS study participants $(n=2172)$

\begin{tabular}{lcccc}
\hline & \multicolumn{3}{c}{ Education status $^{\mathbf{1}}$} & \\
\cline { 2 - 3 } & $\begin{array}{c}\text { Low } \\
\text { B }\end{array}$ & $\begin{array}{c}\text { Intermediate } \\
\text { (n=676) }\end{array}$ & $\begin{array}{c}\text { High } \\
(\mathbf{n}=\mathbf{1 9 8})\end{array}$ & \\
\hline All-cause mortality ${ }^{2}$ & & & & \\
Overall & 40 & $22^{* *}$ & $19^{* *}$ & $<0.001$ \\
Male & 39 & $23^{* *}$ & $19^{* *}$ & $<0.001$ \\
Female & 41 & $17^{* *}$ & $22^{* *}$ & $<0.001$ \\
Fatal or non-fatal ACS events & & & \\
30 d & 29 & 28 & $47^{* *}$ & $<0.001$ \\
1 y & 10 & 11 & 8 & 0.66 \\
10 y & 42 & $30^{* *}$ & $35^{* *}$ & $<0.001$ \\
Male & 44 & $31^{* *}$ & $36^{* *}$ & $<0.001$ \\
Female & 36 & $23^{* *}$ & 30 & 0.02 \\
\hline
\end{tabular}

Values are presented as relative (\%) frequenciy.

ACS, acute coronary syndrome; GREECS, Greek acute coronary syndrome.

'Low education was defined as $<9$ years of school, intermediate education as 9-14 years of school, and high education as $>14$ years of school.

${ }^{2}$ All-cause mortality included acute myocardial infarctions, stroke, cancer, other cardiovascular events, and other causes.

${ }^{* *} p<0.01$ for the comparisons between the high- and intermediateeducation groups vs. the low-education group, after using the Bonferroni rule to correct for probability of the inflation of type I errors due to multiple comparisons.

ing the follow-up period than those with a high educational level (Table 3, model 1). After adjusting for age; sex; BMl; smoking; a history of hypertension, hypercholesterolemia, or diabetes; a family history of CVD (in order to account for the overall burden of CVD risk); and physical activity status, the impact of educational level on all-cause mortality remained significant only among those in the intermediate-education group (Table 3, model 2). When the MedDietScore, which was used to measure the overall dietary habits of the patients (Table 3, model 3) and alcohol consumption, which has been suggested to be a confounder when studying relationships between socioeconomic status and health (Table 3, model 4), were added to model 2 , the relationship between low levels of education and all-cause mortality remained significant (HR, $1.47 ; 95 \% \mathrm{Cl}, 1.00$ to 2.17 ). Alcohol consumption was adjusted for separately from the MedDietScore to avoid co-linearity of these factors in the same model. The inclusion of financial status (Table 3, model 5) did not alter the above relationships, in particular the associations of high/low education status with all-cause mortality in ACS patients ( $\mathrm{HR}, 1.31 ; 95 \% \mathrm{Cl}, 0.89$ to 2.00). Finally, when adherence to medication was added to the final model, an aggravating effect of low and intermediate
Table 3. Results from nested, multi-adjusted Cox proportional hazard models regarding associations between education status and all-cause mortality in ACS patients at10 years of follow-up among participants in the GREECS study $(n=2172)$

\begin{tabular}{|c|c|c|c|c|}
\hline \multicolumn{2}{|c|}{ Education group ${ }^{1}$} & \multirow{2}{*}{$\begin{array}{c}\mathbf{H R} \\
1.53\end{array}$} & \multirow{2}{*}{$\begin{array}{c}\mathbf{9 5 \%} \mathbf{C I} \\
1.09,2.12\end{array}$} & \multirow{2}{*}{$\begin{array}{l}\text { Adjusted } \\
\text { Age, sex }\end{array}$} \\
\hline Model 1 & Low & & & \\
\hline & Intermediate & 1.56 & $1.29,1.88$ & \\
\hline & High & 1.00 & Reference & \\
\hline \multirow[t]{3}{*}{ Model 2} & Low & 1.33 & $0.93,1.92$ & \multirow{3}{*}{$\begin{array}{l}\text { Age, sex, BMI, smoking, } \\
\text { history of hypertension, } \\
\text { hypercholesterolemia, } \\
\text { diabetes, family history } \\
\text { of CVD and physical } \\
\text { activity }\end{array}$} \\
\hline & Intermediate & 1.72 & $1.35,2.22$ & \\
\hline & High & 1.00 & Reference & \\
\hline \multirow[t]{3}{*}{ Model 3} & Low & 1.33 & $0.93,1.92$ & \multirow{3}{*}{$\begin{array}{l}\text { Model } 2 \text { and } \\
\text { MedDietScore }\end{array}$} \\
\hline & Intermediate & 1.72 & $1.35,2.22$ & \\
\hline & High & 1.00 & Reference & \\
\hline \multirow[t]{3}{*}{ Model 4} & Low & 1.47 & $1.00,2.17$ & \multirow{3}{*}{$\begin{array}{l}\text { Model } 2 \text { and alcohol } \\
\text { drinking }\end{array}$} \\
\hline & Intermediate & 1.96 & $1.47,2.63$ & \\
\hline & High & 1.00 & Reference & \\
\hline \multirow[t]{3}{*}{ Model 5} & Low & 1.31 & $0.89,2.00$ & \multirow{3}{*}{$\begin{array}{l}\text { Model } 2 \text { and financial } \\
\text { status }\end{array}$} \\
\hline & Intermediate & 1.78 & $1.35,2.38$ & \\
\hline & High & 1.00 & Reference & \\
\hline \multirow[t]{3}{*}{ Model 6} & Low & 2.08 & $1.14,3.84$ & \multirow{3}{*}{$\begin{array}{l}\text { Model } 2 \text { and adherence } \\
\text { to medication }\end{array}$} \\
\hline & Intermediate & 3.13 & $2.12,4.54$ & \\
\hline & High & 1.00 & Reference & \\
\hline
\end{tabular}

ACS, acute coronary syndrome; GREECS, Greek acute coronary syndrome; $\mathrm{HR}$, hazard ratio; $\mathrm{Cl}$, confidence interval; $\mathrm{BMI}$, body mass index; CVD, cardiovascular disease.

1 Low education was defined as $<9$ years of school, intermediate education as 9-14 years of school, and high education as $>14$ years of school.

educational levels was observed ( $\mathrm{HR}, 2.08 ; 95 \% \mathrm{Cl}, 1.14$ to 3.84 and $\mathrm{HR}, 3.13 ; 95 \% \mathrm{Cl}, 2.12$ to 4.54 , respectively) (Table 3, model 6). In all models, only the intermediate-education group remained significantly associated with all-cause mortality.

\section{Recurrent Acute Coronary Syndrome Events By} Education Level During the 10-Year (2004-2014) Follow-up of Acute Coronary Syndrome Patients

The risk for a short-term fatal or non-fatal ACS event (i.e., within 30 days after hospital discharge) was substantially higher among the high-education group than in the intermediate-education and low-education groups $(p<0.001)$, whereas at one year after hospital discharge no differences were observed among the education groups (Table 2). The highest 10year incidence of recurrent ACS events (fatal or non-fatal) was observed in the low-education group, whereas no significant differences were observed between the intermediate-educa- 


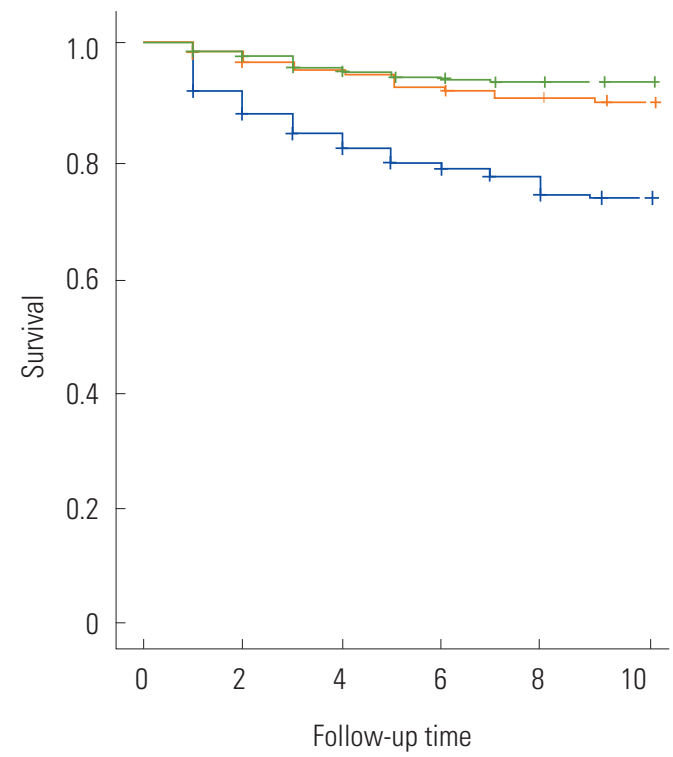

A

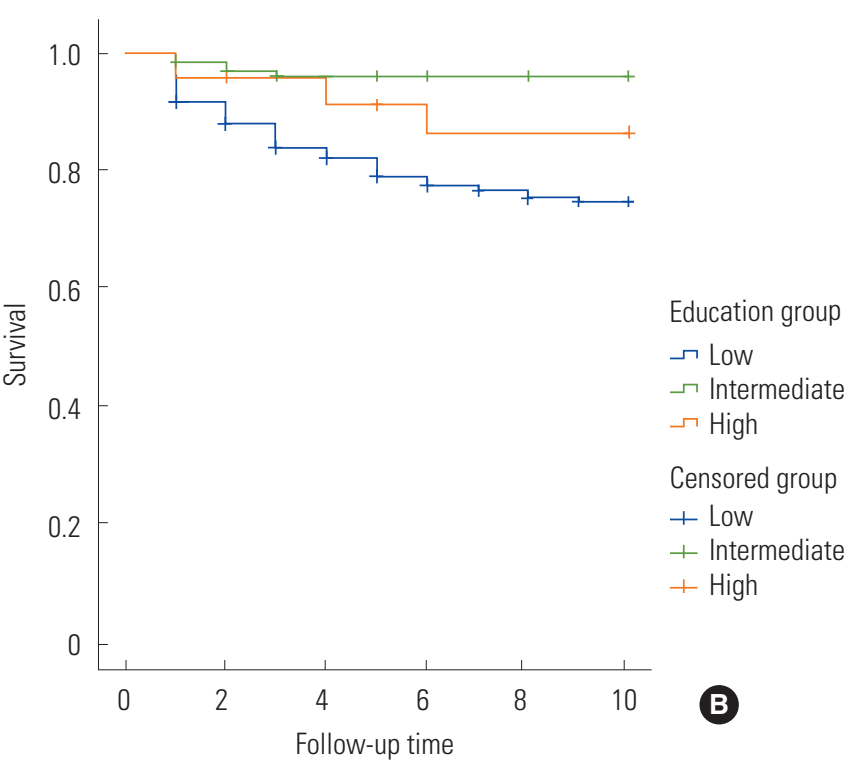

Figure 1. Survival curves for fatal or non-fatal acute coronary syndrome events by educational level ( $<9$ years, $9-14$ years, $>14$ years) over 10 years of follow-up of the Greek acute coronary syndrome study patients (A: male, B: female).

tion and high-education groups. Patients with an intermediate level of education (9 to 14 years of formal education) had a better long-term prognosis than the other two groups (Figure 1, Table 2).

In order to further explore associations between education status and the 10-year incidence of ACS, a multi-adjusted analysis was performed (Table 4). Similarly to all-cause mortality, the intermediate-education group showed a significantly higher unprotected effect than the high-education group. Pa-
Table 4. Results from nested, multi-adjusted Cox-proportional hazard models regarding associations between education status and the incidence of fatal or non-fatal ACS events over 10 years of follow-up among participants in the GREECS study $(n=2172)$

\begin{tabular}{|c|c|c|c|}
\hline Education group ${ }^{1}$ & HR & $95 \% \mathrm{Cl}$ & Adjusted \\
\hline Model 1 Low & 1.28 & $0.93,1.78$ & \multirow[t]{3}{*}{ Age, sex } \\
\hline Intermediate & 1.67 & $1.35,2.04$ & \\
\hline High & 1.00 & Reference & \\
\hline Model 2 Low & 1.25 & $0.88,1.78$ & \multirow{3}{*}{$\begin{array}{l}\text { Age, sex, BMI, smoking, } \\
\text { history of hypertension, } \\
\text { hypercholesterolemia, } \\
\text { diabetes, family history } \\
\text { of CVD and physical } \\
\text { activity }\end{array}$} \\
\hline Intermediate & 1.61 & $1.23,2.08$ & \\
\hline High & 1.00 & Reference & \\
\hline Model 3 Low & 1.25 & $0.88,1.78$ & \multirow{3}{*}{$\begin{array}{l}\text { Model } 2 \text { and } \\
\text { MedDietScore }\end{array}$} \\
\hline Intermediate & 1.61 & $1.23,2.08$ & \\
\hline High & 1.00 & Reference & \\
\hline Model 4 Low & 1.37 & $0.93,2.04$ & \multirow{3}{*}{$\begin{array}{l}\text { Model } 2 \text { and alcohol } \\
\text { drinking }\end{array}$} \\
\hline Intermediate & 1.85 & $1.39,2.43$ & \\
\hline High & 1.00 & Reference & \\
\hline Model 5 Low & 1.31 & $0.88,1.96$ & \multirow{3}{*}{$\begin{array}{l}\text { Model } 2 \text { and financial } \\
\text { status }\end{array}$} \\
\hline Intermediate & 1.47 & $1.11,1.96$ & \\
\hline High & 1.00 & Reference & \\
\hline Model 6 Low & 0.82 & $0.34,2.00$ & \multirow{3}{*}{$\begin{array}{l}\text { Model } 2 \text { and adherence } \\
\text { to medication }\end{array}$} \\
\hline Intermediate & 0.92 & $055,1.54$ & \\
\hline High & 1.00 & Reference & \\
\hline
\end{tabular}

ACS, acute coronary syndrome; GREECS, Greek acute coronary syndrome; $\mathrm{HR}$, hazard ratio; Cl, confidence interval; BMI, body mass index; CVD, cardiovascular disease.

'Low education was defined as $<9$ years of school, intermediate education as 9-14 years of school, and high education as $>14$ years of school.

tients in the low-education group did not seem to be protected in comparison with the high-education group. Similarly, after adjusting for patients' adherence to medication for various comorbidities, no significant effect of educational level on ACS events was observed ( $\mathrm{HR}, 0.82 ; 95 \% \mathrm{Cl}, 0.34$ to 2.00 ) (Table 4, model 6).

\section{DISCUSSION}

The present study is one of the very few cohort studies that have investigated the role of educational attainment on the 10-year disease prognosis among ACS patients. It was documented that the least educated patients had a greater risk of developing recurrent (fatal or non-fatal) cardiac events, as well as all-cause mortality in both sexes, than the most educated patients. Accordingly, differences in the severity of disease 
outcomes were observed among different educational groups. Several studies have demonstrated that education has a significant impact on health [15-17]. However, the mechanisms of this association on the prevention of secondary ACS are not well understood [18]. Low educational status is associated with increased CVD mortality rates among males and females, and it seems to play a major role in the occurrence of CVD [1921]; nevertheless, understanding this relationship among already diseased patients may inform new ways of targeting and treating cardiac patients in the future.

The unadjusted analysis revealed that the least educated patients reported less healthy dietary habits, exhibited more major risk factors for another cardiac event (i.e., hypertension, diabetes mellitus, and obesity), and had more years of smoking than the most educated patients (Table 1). Similarly, the EUROASPIRE II study and the 2007-2010 National Health and Nutritional Examination Survey demonstrated that the educational level of ACS patients was inversely associated with the prevalence of current smoking and that most participants had failed to quit smoking $[22,23]$. In the present study it was also observed that highly educated patients were more physically active than the least educated group. An association between physical activity and CVD was demonstrated in the 1950s by Morris et al. [24], who reported that males with physically active jobs had a lower incidence of coronary heart disease(CHD) than did males with jobs requiring little or no physical activity. Since, then a number of epidemiological studies have demonstrated the cardioprotective effects of regular moderate exercise on the incidence of several chronic diseases, including CHD, and other cardiac outcomes $[25,26]$. The inverse relationship between education disparities and physical activity is probably embedded in the broader paradigm according to which the least educated patients adopt unhealthy lifestyle habits [6]. However, it has been suggested that cultural instead of socioeconomic factors mediate the relationship between education and CVD [27]. Despite the aforementioned associations, patients' education status still independently predicted the 10-year prognosis of ACS, suggesting that other moderating or mediating factors must explain this relationship.

Regarding patients' clinical characteristics, only a history of hypercholesterolemia was more frequent among the high-education group. This may be attributed to the fact that the participants in this group could better control hypertension and diabetes, comply with medication, engage in healthier lifestyle choices, and were more well-off financially, as well as to the possibility that they were diagnosed with hypercholesterolemia more often due to their awareness of their overall medical condition [28]. However, in agreement with the effects of lifestyle factors, the aforementioned disparities in the distribution of cardio-metabolic risk factors by educational level did not affect the association of educational status with 10-year ACS prognosis.

It was also found that the participants in the low-education group were less likely to be obese, in contrast with the prevailing view that obesity is inversely associated with educational level. It seems that over the most recent years, the epidemic of obesity has affected more highly educated groups [29]. Additionally, very recent data suggest that although highly educated people may have more social and financial opportunities, they tend to be employed in more strenuous and demanding positions and are less likely to participate in outdoor recreational activities and, as such, are at an increased risk of obesity, smoking, and excess alcohol consumption, and most likely at a greater risk of CVD [30]. In agreement with previous studies, the present work revealed a U-shaped association between ACS prognosis and education status, with the least and most educated patients negatively affected by lifestyle-related risk factors [31]. A non-linear relationship between education and mortality risk was also observed in a previous study showing that high school graduates had better physical functioning than their counterparts with lower or higher educational levels [32]. Regarding disease progression, it was observed that the high-education group had worse short-term prognoses (30-day ACS events), while the low-education group had worse long-term prognoses (10-year ACS events). Although it has been proposed that socioeconomically deprived patients have higher in-hospital or short-term mortality rates than their less deprived counterparts, the data are inconclusive, indicating the absence of a clear association between socioeconomic background and the short-term course of disease [33]. The fact that at the end of the follow-up period the least educated patients had worse prognoses may be attributed to the quality of disease management due to financial restrictions. Indeed, it has been stated that participation in secondary prevention programs depends mainly on education and income [34]. Low financial status, as another determinant of social class, has been associated with higher 10-year all-cause mortality rates and a higher risk of recurrent ACS events, and this tendency has been attributed to the adoption of unhealthy lifestyle habits and decreased compliance to therapeutic regi- 
mens due to financial constraints [35].

Finally, taking into account the likelihood that adherence to medication mediated the effect of education on ACS risk, it could be speculated that patients' financial status during the 10-year follow-up period may have affected adherence to medications (Table 4). Moreover, the recent financial crisis has mainly affected people with low levels of education by increasing their likelihood of unemployment [36].

\section{Limitations}

The present study, despite its strong findings with specific public health implications, has some limitations that should be acknowledged in order to better interpret the results. In studies that use self-reported data, social desirability reporting bias is possible in subjects with both higher and lower educational levels; the former tend to be more aware of the characteristics of a healthy diet and have more knowledge about which food items are healthier, while the latter tend to present a more desirable profile. Additionally, educational level was used as the only indicator of socioeconomic status, although our data also included other social determinants, such as the patients' financial status. All patient characteristics were measured once, at the baseline examination, and therefore may have been prone to life-course changes during the decade of follow-up. This consideration may influence the robustness of our findings.

In summary, the present 10-year follow-up study revealed that ACS patients with a low level of education were at a higher risk for fatal or non-fatal ACS events as well as for all-cause mortality, irrespective of their lifestyle and clinical characteristics. Low educational status had an adverse effect on longterm ACS incidence as well as on all-cause mortality among cardiac patients. Moreover, high educational levels did not appear to be as protective as has been argued, particularly regarding cardiac outcomes. In light of the recent financial crisis, emphasis should be placed on the pursuit of cost-effective healthcare services, especially among poorly educated and chronically ill patients, in order to close the gap in health disparities. The issues of inequalities in treatment, non-adherence to medical recommendations, and health literacy still remain a great public health challenge. The present analysis implies that less educated patients may be regarded as an emerging high-risk social group in the context of public health intervention strategies.

\section{ACKNOWLEDGEMENTS}

The authors would like to thank the field investigators of the Greek acute coronary syndrome (GREECS) study (Athanasios Karanasios, Lambros Rizos, Michalis Mparmparoussis, George Kassimatis, George Giannopoulos, Sophia Arapi, Theodoros Gialernios, Constandina Massoura, Skevos Sideris, Nick Daskalopoulos, Eleni Tsompanaki, Moscho Michalopoulou, Eleni Kalli, Margarita Verdi, Nikos Vasileiou, Evangelos Papataxiarchis, Despoina Tzanoglou, Georgia Kouli, Semina Kouroupi, Marifei Balli, Ifigenia Stergiouli, and Vivi Tsomboli) for their support in the clinical evaluation of the patients and Alexandros Chalamandaris for database management.

\section{CONFLICT OF INTEREST}

The authors have no conflicts of interest associated with the material presented in this paper.

\section{ORCID}

Demosthenes B. Panagiotakos http://orcid.org/0000-00018583-153X

\section{REFERENCES}

1. Marmot MG, Kogevinas M, Elston MA. Social/economic status and disease. Annu Rev Public Health 1987;8:111-135.

2. Kaplan GA, Keil JE. Socioeconomic factors and cardiovascular disease: a review of the literature. Circulation 1993;88(4 Pt 1):1973-1998

3. National Bureau of Economic Research. The effects of education on health; 2014 [cited 2015 Sep 9]. Available from: http:// www.nber.org/digest/mar07/w12352.html.

4. Beauchamp A, Peeters A, Wolfe R, Turrell G, Harriss LR, Giles $\mathrm{GG}$, et al. Inequalities in cardiovascular disease mortality: the role of behavioural, physiological and social risk factors. J Epidemiol Community Health 2010;64(6):542-548.

5. World Health Organization. The determinants of health [cited 2015 Sep 9]. Available from: http://www.who.int/hia/evidence/doh/en/.

6. Pitsavos CE, Panagiotakos DB, Chrysohoou CA, Skoumas J, Stefanadis C, Toutouzas PK. Education and acute coronary syndromes: results from the CARDIO2000 epidemiological study. Bull World Health Organ 2002;80(5):371-377. 
7. World Health Organization; Commission on Social Determinants of Health. Closing the gap in a generation: health equity through action on the social determinants of health; 2008 [cited 2015 Sep 11]. Available from: http://www.who.int/social_determinants/final_report/csdh_finalreport_2008_execsumm.pdf.

8. Mayer O Jr, Simon J, Heidrich J, Cokkinos DV, De Bacquer D; EUROASPIRE II Study Group. Educational level and risk profile of cardiac patients in the EUROASPIRE II substudy. J Epidemiol Community Health 2004;58(1):47-52.

9. Kelly-Irving M, Delpierre C, Schieber AC, Lepage B, Rolland C, Afrité $A$, et al. Do general practitioners overestimate the health of their patients with lower education? Soc Sci Med 2011;73(9):1416-1421.

10. Pitsavos C, Panagiotakos DB, Antonoulas A, Zombolos S, Kogias $Y$, Mantas $Y$, et al. Epidemiology of acute coronary syndromes in a Mediterranean country; aims, design and baseline characteristics of the Greek study of acute coronary syndromes (GREECS). BMC Public Health 2005;5:23.

11. Antman E, Bassand JP, Klein W, Ohman M, Lopez Sendon JL, Rydén $\mathrm{L}$, et al. Myocardial infarction redefined--a consensus document of The Joint European Society of Cardiology/American College of Cardiology Committee for the redefinition of myocardial infarction. Eur Heart J 2000;21(18):1502-1513.

12. Braunwald E. Heart disease: a textbook of cardiovascular medicine. 5th ed. Philadelphia: Saunders; 1997, p.1187-1188.

13. Panagiotakos DB, Pitsavos C, Arvaniti F, Stefanadis C. Adherence to the Mediterranean food pattern predicts the prevalence of hypertension, hypercholesterolemia, diabetes and obesity, among healthy adults; the accuracy of the MedDietScore. Prev Med 2007;44(4):335-340.

14. Pate RR, Pratt M, Blair SN, Haskell WL, Macera CA, Bouchard C, et al. Physical activity and public health. A recommendation from the Centers for Disease Control and Prevention and the American College of Sports Medicine. JAMA 1995;273(5):402407.

15. Capewell S, Allender S, Critchley J, Lloyd-Williams F, O'Flaherty M, Rayner M, et al. Modelling the UK burden of cardiovascular disease to 2020. London: Cardio \& Vascular Coalition and the British Heart Foundation; 2008, p. 35-38.

16. Cutler DM, Lleras-Muney A. Understanding differences in health behaviors by education. J Health Econ 2010;29(1):1-28.

17. Stelmach W, Kaczmarczyk-Chałas K, Bielecki W, Stelmach I, Drygas $W$. How income and education contribute to risk factors for cardiovascular disease in the elderly in a former Com- munist country. Public Health 2004;118(6):439-449.

18. Devaux M, Sassi F, Church J, Cecchini M, Borgonovi F. Exploring the relationship between education and obesity. OECD J Econ Stud 2011. doi: http://dx.doi.org/10.1787/eco_studies2011-5kg5825v1k23.

19. Kalediene R, Petrauskiene J. Inequalities in mortality by education and socio-economic transition in Lithuania: equal opportunities? Public Health 2005;119(9):808-815.

20. Kirchberger I, Meisinger C, Golüke H, Heier M, Kuch B, Peters A, et al. Long-term survival among older patients with myocardial infarction differs by educational level: results from the MONICA/KORA myocardial infarction registry. Int J Equity Health 2014;13:19.

21. Reques L, Giráldez-García C, Miqueleiz E, Belza MJ, Regidor E. Educational differences in mortality and the relative importance of different causes of death: a 7-year follow-up study of Spanish adults. J Epidemiol Community Health 2014;68(12): 1151-1160.

22. Kotseva K, Wood D, De Backer G, De Bacquer D, Pyörälä K, Keil $\mathrm{U}$, et al. Cardiovascular prevention guidelines in daily practice: a comparison of EUROASPIRE I, II, and III surveys in eight European countries. Lancet 2009;373(9667):929-940.

23. Tang L, Patao C, Chuang J, Wong ND. Cardiovascular risk factor control and adherence to recommended lifestyle and medical therapies in persons with coronary heart disease (from the National Health and Nutrition Examination Survey 2007-2010). Am J Cardiol 2013;112(8):1126-1132.

24. Morris JN, Heady JA, Raffle PA, Roberts CG, Parks JW. Coronary heart-disease and physical activity of work. Lancet 1953;265 (6796):1111-1120.

25. Taylor RS, Brown A, Ebrahim S, Jolliffe J, Noorani H, Rees K, et al. Exercise-based rehabilitation for patients with coronary heart disease: systematic review and meta-analysis of randomized controlled trials. Am J Med 2004;116(10):682-692.

26. Sattelmair J, Pertman J, Ding EL, Kohl HW 3rd, Haskell W, Lee IM. Dose response between physical activity and risk of coronary heart disease: a meta-analysis. Circulation 2011;124(7): 789-795.

27. Janković S, Stojisavljević D, Janković J, Erić M, Marinković J. Association of socioeconomic status measured by education, and cardiovascular health: a population-based cross-sectional study. BMJ Open 2014;4(7):e005222.

28. Estoppey D, Paccaud F, Vollenweider P, Marques-Vidal P. Trends in self-reported prevalence and management of hypertension, hypercholesterolemia and diabetes in Swiss 
adults, 1997-2007. BMC Public Health 2011;11:114.

29. Singh GK, Siahpush M, Hiatt RA, Timsina LR. Dramatic increases in obesity and overweight prevalence and body mass index among ethnic-immigrant and social class groups in the United States, 1976-2008. J Community Health 2011;36(1):94110.

30. Tsai SY. A study of the health-related quality of life and workrelated stress of white-collar migrant workers. Int J Environ Res Public Health 2012;9(10):3740-3754.

31. Sethi R, Puri A, Makhija A, Singhal A, Ahuja A, Mukerjee S, et al. "Poor man's risk factor": correlation between high sensitivity C-reactive protein and socio-economic class in patients of acute coronary syndrome. Indian Heart J 2008;60(3):205-209.

32. Montez JK, Hummer RA, Hayward MD. Educational attainment and adult mortality in the United States: a systematic analysis of functional form. Demography 2012;49(1):315-336.

33. Pilote L, Tu JV, Humphries K, Behouli H, Belisle P, Austin PC, et al. Socioeconomic status, access to health care, and outcomes after acute myocardial infarction in Canada's universal health care system. Med Care 2007;45(7):638-646.

34. Huber D, Henriksson R, Jakobsson S, Stenfors N, Mooe T. Implementation of a telephone-based secondary preventive intervention after acute coronary syndrome (ACS): participation rate, reasons for non-participation and 1-year survival. Trials 2016;17:85.

35. Notara V, Panagiotakos DB, Pitsavos C, Kogias Y, Stravopodis P, Papanagnou $G$, et al. Lower financial status and adherence to medication determines 10-year (2004-2014) all-cause mortality and risk for acute coronary syndrome incidence among cardiac patients: the GREECS study. Curr Vasc Pharmacol 2015; 13(6):771-777.

36. Organization for Economic Cooperation and Development. Education at a glance 2013: OECD indicators [cited 2015 Oct 15]. Available from: http://www.oecd.org/edu/eag2013\%20 (eng)--FINAL\%2020\%20June\%202013.pdf. 